Document downloaded from:

http://hdl.handle.net/10251/50681

This paper must be cited as:

Robles Martínez, A.; Ruano García, MV.; Ribes Bertomeu, J.; Seco Torrecillas, A.; Ferrer, J. (2014). Global sensitivity analysis of a filtration model for submerged anaerobic membrane bioreactors (AnMBR). Bioresource Technology. 158:365-376. doi:10.1016/j.biortech.2014.02.087.

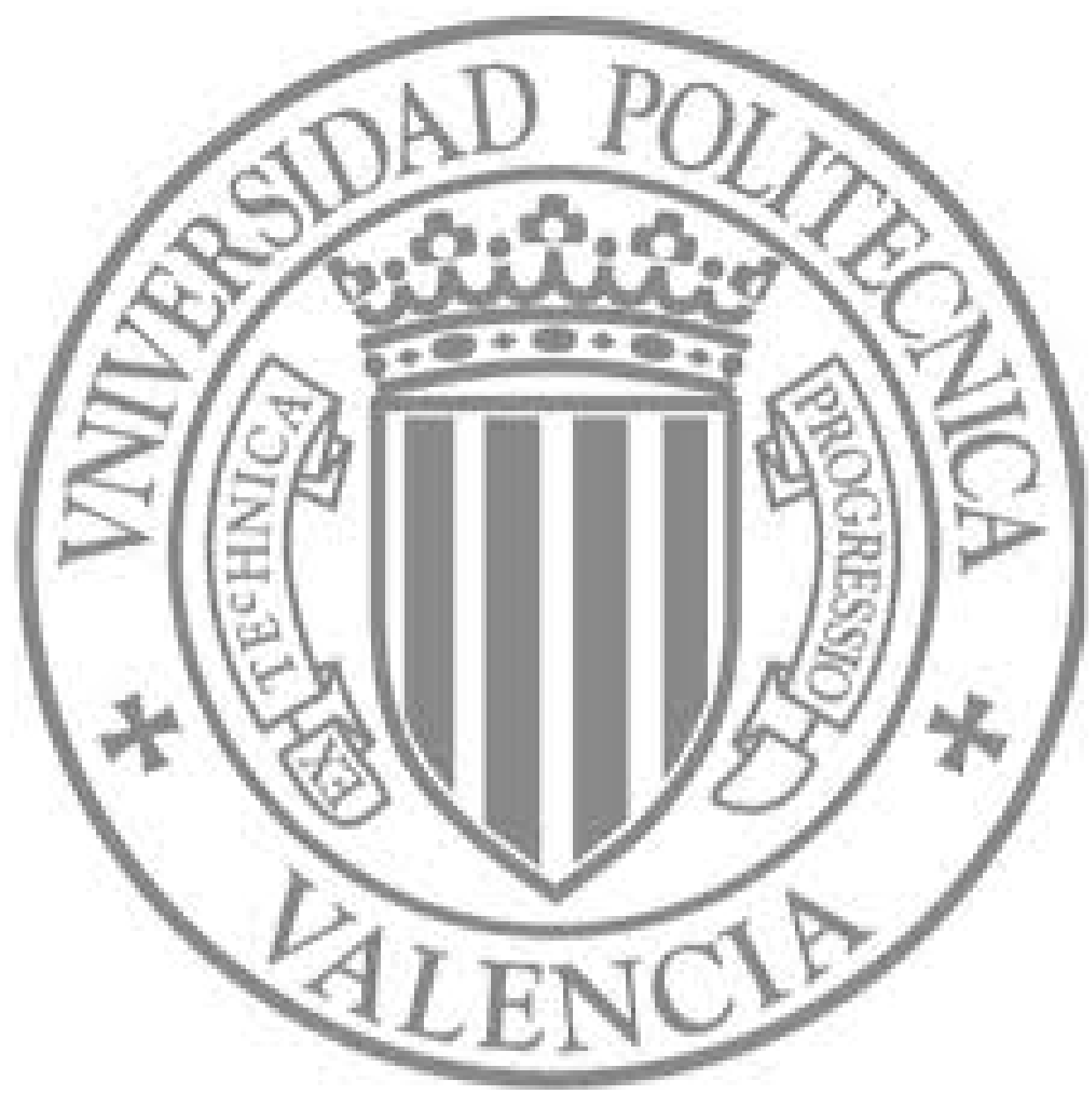

The final publication is available at

http://dx.doi.org/10.1016/j.biortech.2014.02.087

Copyright Elsevier 


\title{
Global sensitivity analysis of a filtration model for submerged anaerobic membrane bioreactors (AnMBR)
}

\author{
A. Robles ${ }^{a, *}$, M.V. Ruano ${ }^{\mathrm{a}, 1}$, J. Ribes $^{\mathrm{a}}$, A. Seco ${ }^{\mathrm{a}}$ and J. Ferrer ${ }^{\mathrm{b}}$ \\ a Departament d'Enginyeria Química, Escola Tècnica Superior d'Enginyeria, Universitat de \\ València, Avinguda de la Universitat s/n, 46100 Burjassot, Valencia, Spain (e-mail: \\ angel.robles@uv.es; mavictoria.ruano.garcia@fcc.es; josep.ribes@uv.es; aurora.seco@uv.es) \\ b Institut Universitari d'Investigació d'Enginyeria de l'Aigua i Medi Ambient, IIAMA, \\ Universitat Politècnica de València, Camí de Vera s/n, 46022 Valencia, Spain (e-mail: \\ jferrer@hma.upv.es) \\ * Corresponding author: tel. +34 9638799 61, fax +34 9638790 09, e-mail: \\ angel.robles@uv.es
}

\begin{abstract}
The results of a sensitivity analysis of a filtration model for submerged anaerobic MBRs (AnMBRs) are assessed in this paper. This study aimed to (1) identify the less-(or non-) influential factors of the model in order to facilitate model calibration and (2) validate the modelling approach (i.e. to determine the need for each of the proposed factors to be included in the model). The sensitivity analysis was conducted using a revised version of the Morris screening method. The dynamic simulations were conducted using long-term data obtained from an AnMBR plant fitted with industrial-scale hollow-fibre membranes. Of the 14 factors in the model, six were identified as influential, i.e. those calibrated using off-line protocols. A dynamic calibration (based on optimisation algorithms) of these influential factors was conducted. The resulting estimated model factors accurately predicted membrane performance.
\end{abstract}

\footnotetext{
${ }^{1}$ Present address: aqualia, gestión integral del agua, S.A. Avenida del Camino de Santiago, 4028050 Madrid, Spain
} 


\section{Keywords}

Filtration model; global sensitivity analysis; industrial-scale hollow-fibre

membranes; Morris screening method; submerged anaerobic membrane bioreactor

(AnMBR)

\section{Highlights}

A global sensitivity analysis of a filtration model for AnMBRs was conducted.

It was conducted using a revised version of the Morris screening method.

Sensitivity results significantly simplified the input subset to be calibrated.

Only one input factor could be removed from the model.

\section{Introduction}

Understanding and optimising a complex system such as a membrane bioreactor (MBR) is a difficult and time-consuming process mainly because of the large number of sub-processes taking place simultaneously, which are generally highly dependent upon each other. In this respect, mathematical modelling is a powerful tool for studying such complex systems (Naessens et al., 2012).

Certain models have been found to be useful for dealing with different aspects of WWTPs, e.g. R\&D of wastewater treatment processes, design and upgrading of WWTPs, and the development of operating and control strategies designed to optimise process performance (Ferrer et al., 2004; Derbal et al., 2009; Ruano et al., 2012b). Computerised models make it possible to perform many virtual experiments in a short space of time. Therefore the mathematical modelling of filtration in submerged anaerobic MBRs (AnMBRs) may help gain an insight into the key factors in membrane fouling (Mannina et al., 2011), and are also invaluable for the design, prediction and 
control of the membrane technology used for treating wastewater ( $\mathrm{Ng}$ and $\mathrm{Kim}, 2007)$. However, predictions made on the basis of models are not free from uncertainty because models are an abstract approximation of reality and are usually based on a considerable number of assumptions. In this respect, sensitivity analysis provides useful information for modellers because it attempts to quantify how changes to a model's input factors affect the model's output. In addition, due to the limited data available about full-scale systems, the subset of identifiable factors can be reduced, which makes calibrating the model simpler.

The different sensitivity analysis strategies applied in literature are usually classified in two main categories: global sensitivity analysis (GSA) which involves sampling and whose range of input uncertainty reflects the uncertainty in the output variables; and local sensitivity analysis, which is based on the local impact of input factors upon output variables.

The Morris screening method (Morris, 1991) is a one-at-a-time (OAT) method of GSA which calculates the elementary effects $\left(E E_{i}\right)$ of input factors upon the output of a model. This screening method makes it possible to validate the modelling approach because it identifies the non-influential input factors, which could be useful for improving the definition of the model by evaluating the usefulness of the non-influential input factors.

One key issue with the Morris screening method is that the sampling matrix is generated at random. This random sampling may not represent the sampling space well and result in an inadequate screening of non-influential input factors. In this regard, Campolongo et al. (2007) proposed an improved sampling method which maximised the 
distances between the final trajectories $(r)$ selected. However, this improved sampling was not suitable for large models because of the vast numbers of calculations needed to determine the best combinations. For this reason, Ruano et al. (2012a) proposed an improved sampling method based on trajectory design intended to overcome the great many calculations required by the Campolongo sampling method.

In this study, a revised version of the Morris screening method that includes an improved sampling method (Ruano et al., 2012a) was applied to a filtration model (resistance-in-series-based) for submerged AnMBRs (Robles et al., 2013a; 2013b). Although the model was proven to be robust, the Morris screening method was used not only to identify the less/non-influential input factors of the model, but also to validate the modelling approach (i.e. to assess the need to include each of the proposed factors in the model). In addition, a dynamic calibration (based on optimisation algorithms) of the most influential input factors was conducted.

\section{Materials and methods}

\subsection{AnMBR plant description}

The filtration model evaluated in this study was developed, calibrated and validated using data obtained from a AnMBR system fitted with industrial-scale submerged hollow-fibre (HF) membranes and fed with urban wastewater from the pre-treatment of the Carraixet WWTP (Valencia, Spain). The plant consists of an anaerobic reactor with a total volume of $1.3 \mathrm{~m}^{3}\left(0.4 \mathrm{~m}^{3}\right.$ head space for biogas $)$ connected to two membrane tanks each with a total volume of $0.8 \mathrm{~m}^{3}\left(0.2 \mathrm{~m}^{3}\right.$ head space for biogas $)$. Each membrane tank (MT) has one industrial HF ultrafiltration membrane unit (PURON ${ }^{\circledR}$, 
Koch Membrane Systems (PUR-PSH31) with $0.05 \mu$ m pores). Each module has a total membrane surface of $30 \mathrm{~m}^{2}$. For further details of this AnMBR system, see Robles et al. (2013c).

\subsection{Monitoring system}

In addition to being monitored on line, grab samples of anaerobic sludge were taken once a day to assess filtration performance. MLTS concentration was determined according to Standard Methods (2005) using procedure 2540 B.

\subsection{Model description}

The filtration model used in this study (Robles et al., 2013a; 2013b) gives the dynamic evolution of the transmembrane pressure (TMP) by applying Eq. 1 and Eq. 2 .

$$
\operatorname{TMP}(t)=J \cdot \mu \cdot R_{T}
$$

where:

- $\quad J$ is the transmembrane flux $\left(\mathrm{m} \mathrm{s}^{-1}\right)$

- $\quad \mu$ is the permeate dynamic viscosity $\left(\mathrm{kg} \mathrm{m}^{-1} \mathrm{~s}\right)$

- $T M P(t)$ is the transmembrane pressure $(\mathrm{Pa})$

- $R_{T}$ is the total filtration resistance $\left(\mathrm{m}^{-1}\right)$

$$
R_{T}=R_{M}+R_{C}+R_{I}=R_{M}+\omega_{C} \cdot \alpha_{C}+\omega_{I} \cdot \alpha_{I}
$$

where:

- $R_{M}$ is the intrinsic membrane resistance $\left(\mathrm{m}^{-1}\right)$ 
- $R_{C}$ is the cake layer resistance $\left(\mathrm{m}^{-1}\right)$

- $\quad R_{I}$ is the irreversible fouling resistance $\left(\mathrm{m}^{-1}\right)$

- $\omega_{C}$ is the mass of cake deposited per membrane area $\left(\mathrm{kg} \mathrm{m}^{-2}\right)$

- $\quad \alpha_{C}$ is the average specific cake resistance $\left(\mathrm{m} \mathrm{kg}^{-1}\right)$

- $\quad \omega_{I}$ is the mass of irreversible fouling per membrane area $\left(\mathrm{kg} \mathrm{m}^{-2}\right)$

- $\quad \alpha_{I}$ is the average specific irreversible fouling resistance $\left(\mathrm{m} \mathrm{kg}^{-1}\right)$

To account for cake layer compression, $\alpha_{C}$ was defined as time- and TMPdependent as per Bugge et al. (2012) and Jørgensen et al. (2012). In addition, to account for sub-critical fouling, an additional dependence of $\alpha_{C}$ on time was considered in the model (Robles et al., 2013a), as shown in Eq. 3 below:

$\alpha_{C}(t)=\alpha_{C}(t-\Delta t)+\max \left(k_{S F}, k_{t} \cdot\left(\alpha_{C, 0} \cdot\left(1+\frac{T M P}{T M P_{a}}\right)-\alpha_{C}(t-\Delta t)\right)\right) \cdot \Delta t$

Where:

- $\alpha_{C}(t)$ is the specific resistance of the cake at time $t\left(\mathrm{~kg} \mathrm{~m}^{-2}\right)$.

- $\quad \alpha_{C}(t-\Delta t)$ is the specific resistance of the cake at a previous moment in time $(\mathrm{kg}$ $\left.m^{-2}\right)$

- $\quad k_{S F}$ is the parameter related to sub-critical fouling $\left(\mathrm{kg} \mathrm{m}^{-2} \mathrm{~s}^{-1}\right)$.

- $\quad \alpha_{C, 0}$ is the specific resistance of the cake at zero pressure $\left(\mathrm{kg} \mathrm{m}^{-2}\right)$

- $\quad T M P_{a}$ is the pressure needed to double the specific resistance $(\mathrm{Pa})$

- $\quad k_{t}$ is the time constant $\left(\mathrm{s}^{-1}\right)$.

- $\Delta \mathrm{t}$ is the time step (s). 
To model the dynamics of $\omega_{C}$ and $\omega_{I}$ a black-box approach was adopted in the model. This approach considers 3 suspended components: MLTS concentration $X_{T S}$ $\left(\mathrm{kg} \mathrm{TS} \mathrm{m}{ }^{-3}\right)$; dry mass of cake on the membrane surface, $X_{m_{C}}(\mathrm{~kg} \mathrm{TS})$; and dry mass of irreversible fouling on the surface of the membrane, $X_{m_{I}}(\mathrm{~kg} \mathrm{TS})$. In addition, this approach includes four kinetically governed physical processes: (1) cake layer build-up during filtration; (2) cake layer removal using biogas sparging to scour the membrane; (3) cake layer removal during back-flushing; and (4) consolidation of irreversible fouling. Table 1 shows the stoichiometry and kinetic formulae of the four processes considered in the model.

Process 1 (cake layer build-up) is the convective transport of foulants ( $X_{\mathrm{TS}}$ in the model) to the membrane, which is a function of the permeate flow-rate, $Q_{20 P}\left(\mathrm{~m}^{3} \mathrm{~s}^{-1}\right)$, and bulk concentration $\left(X_{\mathrm{TS}}\right)$. Process 2 (membrane scouring by biogas sparging) is the impact of the hydrodynamic conditions in the membrane tank caused by biogas sparging (measured as $\mathrm{BRF}_{\mathrm{V}}$ : biogas recycling flow per bulk volume in the membrane tank). A maximum membrane scouring velocity $\left(q_{\mathrm{MS}, \mathrm{Max}}\right)$ was defined for process 2 . In process 3, the back-flushing removal rate is defined as a function of the back-flushing flow rate, $Q_{2 O B F}\left(\mathrm{~m}^{3} \mathrm{~s}^{-1}\right)$, and $X_{m_{C}}$. As per Sarioglu et al. (2012), a maximum back-flushing removal velocity was defined, $q_{\mathrm{BF}, \mathrm{Max}}\left(\mathrm{m}^{-3}\right)$, for process 3 .

One half-saturation switching function $\left(M_{X_{m_{C}}}\right.$, Eq. 4) for both membrane scouring (process 2) and back-flushing (process 3) was used to vary the removal of solids smoothly as the cake layer disappeared (Sarioglu et al., 2012).

$$
M_{X_{m_{C}}}=\frac{X_{m_{C}}}{K_{S, X_{m_{C}}}+X_{m_{C}}}
$$


where:

- $\quad K_{S, X_{m_{C}}}$ is the half-saturation coefficient of cake solids during membrane scouring and back-flushing (kg ST).

Process 2 includes one sigmoid inhibition function $\left(I_{M S}\right.$, Eq. 5) to model the impact of filtering above or below critical conditions.

$$
I_{M S}=\frac{1}{1+K_{F} \cdot e\left(J_{20} \cdot\left(\beta_{1} \cdot B R F_{V}+\beta_{2} \cdot M L T S+\gamma\right)\right)}
$$

where:

- $K_{F}$ is the adjustment parameter representing the fouling rate when the gross 20 ${ }^{\circ} \mathrm{C}$-normalised transmembrane flux $\left(J_{20}\right)$ tends to zero $\left(\mathrm{Pa} \mathrm{s}^{-1}\right)$.

- $\mathrm{J}_{20}$ is the gross $20^{\circ} \mathrm{C}$-normalised transmembrane flux $\left(\mathrm{m} \mathrm{s}^{-1}\right)$.

- $B R F_{V}$ is the biogas recycling flow per bulk volume in the membrane tank $\left(\mathrm{Nm}^{3}\right.$ $\left.\mathrm{s}^{-1} \mathrm{~m}^{-3}\right)$

- $\quad$ MLTS is the mixed liquor total solids concentration $\left(\mathrm{kg} \mathrm{m}^{-3}\right)$.

- $\quad \beta_{1}\left(\mathrm{~s}^{2} \mathrm{~m}^{-1}\right), \beta_{2}\left(\mathrm{~s} \mathrm{~m}^{2} \mathrm{~kg}^{-1}\right)$ and $\gamma\left(\mathrm{s} \mathrm{m}^{-1}\right)$ are the parameters of the model.

On the basis of long-term experimental results, the value of $\gamma$ was defined as a function of $\mathrm{R}_{\mathrm{I}}$ to account for the reduction over time in the filtering capacity of the membranes due to the onset of irreversible fouling. This dependence on irreversible fouling can be expressed as:

$\gamma_{t}=\gamma_{0}-\left(R_{I_{t}}-R_{I_{0}}\right) k_{R I}$ (Eq. 6) 
where:

- $\gamma_{t}$ is the value of $\gamma$ at time $t\left(\mathrm{~s} \mathrm{~m}^{-1}\right)$.

- $\quad \gamma_{0}$ is the value of $\gamma$ at the initial time $\left(\mathrm{s} \mathrm{m}^{-1}\right)$.

- $\quad R_{I_{t}}$ is the irreversible fouling resistance at time $t\left(\mathrm{~m}^{-1}\right)$.

- $\quad R_{I_{0}}$ is the irreversible fouling resistance at the initial time $\left(\mathrm{m}^{-1}\right)$.

- $\quad k_{R I}$ is the proportional constant (s).

Finally, irreversible fouling (process 4) was given in the evaluated model as a direct function of $X_{m_{C}}$ and a maximum irreversible fouling kinetic constant, $q_{\mathrm{IF}, \mathrm{Max}}\left(\mathrm{s}^{-1}\right)$.

This filtration model features a total of 14 factors that must be calibrated for each specific system (see Table 2). These factors were previously calibrated by off-line and dynamic calibration methods using short-term and long-term data from the AnMBR plant (Robles et al., 2013a; 2013b). In addition, on the basis of expert knowledge, default values were assigned to those factors that could not be estimated from the available data (Robles et al., 2013a). Table 2 shows these default values calibrated beforehand and used in the sensitivity analysis carried out in this study.

\subsection{Simulation}

This study included 1 month of dynamic simulations using data obtained from the above-mentioned AnMBR system. This period was selected as a compromise between obtaining reliable results and the cost of calculations. It is important to note that the simulation period must be sufficiently long to enable the effect of both reversible and irreversible fouling mechanisms to be evaluated (Drews, 2010). 
Simulation entailed the following dynamic operating conditions recorded during the long-term performance of the AnMBR plant: MLTS levels from approx. 15 - $18 \mathrm{~g} \mathrm{~L}^{-1}$; biogas recycling flow (BRF) from 4 to $12 \mathrm{Nm}^{3} \mathrm{~h}^{-1}$; and $\mathrm{J}_{20}$ from approx. 4 to $12 \mathrm{LMH}$. The dynamics in $\mathbf{J}_{20}$ considered the fluctuations in the influent flows of WWTPs. For this purpose, the standard dry-weather influent records (updated in 2006) recommended by Copp (1999) were used as shown in Robles et al. (2013d).

\subsection{Morris screening method}

The Morris screening method (Morris, 1991) is a one-factor-at-a-time method of GSA that evaluates the distribution $\left(F_{i}\right)$ of the elementary effects $\left(E E_{i}\right)$ of each input factor upon model outputs, used to calculate the statistical parameters that provide sensitivity data. In this study the scaled elementary effect $\left(S E E_{i}\right)$ proposed by Sin and Gernaey (2009) was applied. $E E_{i}$ is in itself a local measure of sensitivity, but this drawback is overcome by repeating EEi calculations in the input region of interest using Morris's efficient random sampling strategy, which is obtained by using a trajectorybased design. This sampling strategy then evaluates the EEi of each input factor with the same step size but at different initial points in the input region of interest. Finally, the analysis of $F i$ of the elementary effects of each input factor will determine the relative importance of the input factors, providing a good approximation of a GSA.

The finite distribution of elementary effects associated with each input factor $F_{i}$ is commonly obtained by sampling different coordinates $(X)$ from the input space at random. However, this random sampling of $X$ may only cover a small part of the space. Therefore, in this study the trajectory-based sampling strategy proposed in Ruano et al. 
(2012a) was applied. This strategy is based on the improved sampling proposed by Campolongo et al. (2007), which consists in selecting the $r$ trajectories in such a way as to maximise their dispersion in the input space. At first, a high number of random Morris trajectories $M$ are generated and then the highest spread $\mathrm{r}$ trajectories are chosen out of $M$. This spread is calculated following the definition of distance between a couple of trajectories $m$ and $l$ defined by Eq. 7 .

$d_{m l}=\left\{\sum_{i=1}^{k+1} \sum_{j=1}^{k+1} \sqrt{\sum_{z=1}^{k}\left[X_{i}^{m}(z)-X_{j}^{l}(z)\right]^{2}}\right.$ for $m \neq l$ otherwise $d_{m l}=0$

where:

- $\quad X_{i}^{m}(z)$ indicates the $z$ th coordinate of the $i$ th point of the $m$ th Morris trajectory.

Consequently, the best $r$ trajectories out of $M$ are selected by maximising the distance $d_{m l}$ among them, and thus, the quantity $D$, which is the sum of all the distances $d_{m l}$ between couple of trajectories belonging to the combination. This $D$ quantity must be calculated for each possible combination of $r$ trajectories. Consequently, the evaluation of all the possible combinations results in a high computational demand. To solve this problem Ruano et al. (2012a) developed an alternative methodology which does not take into account all the possible combinations, but it gets a combination of $r$ trajectories out of $M$ that are really close to the highest spread one and with low computational demand. Although the proposed sampling does not guarantee maximum overall distances between the final trajectories $(r)$ selected (i.e. maximum dispersion in the input space), at least these distances are maximised locally. For further details on this trajectory-based sampling strategy and its comparison with to the Morris' random strategy see Ruano et al. (2012a). 
As per Saltelli et al. (2004), the mean $(\mu)$, standard deviation $(\sigma)$ and absolute mean $\left(\mu^{*}\right)$ of the $S E E_{i}$ values of each $F_{i}$ were used in this study as sensitivity measures. In accordance with Campolongo et al. (2007), it is required to evaluate $\mu$ and $\sigma$ simultaneously to reliably assess stability rankings since an input factor with elementary effects of different sign would have a low value of $\mu$ but a considerable value of $\sigma$ (i.e. identifiable input factors affecting the output non-linearly or interactively). To overcome this problem, as suggested in Campolongo et al. (2007), $\mu^{*}$ was used in this study to rank the input factors in order to systematically identify the optimal number of repetitions of elementary effects calculations (i.e. $\left.r_{o p t}\right) . \mu^{*}$ can be also used to systematically differentiate between non-influential input factors (low $\left.\mu^{*}\right)$ and influential input factors (high $\mu^{*}$ ). $r_{\text {opt }}$ for each $F_{i}$ was sought with a constant resolution of $p=4$. In order to identify $r_{o p t}, r$ was sequentially increased until the ranking of input factors remained nearby stable, i.e. type II error was minimised (type II error: identifying an important factor as insignificant). This stability was numerically evaluated using a modified version of the position index $P F_{r i \rightarrow r j}$ proposed by Ruano et al. (2012a). For given rankings obtained by $r_{i}$ and $r_{j}$, this modified index $P F_{r i \rightarrow r j}$ is defined by Eq. 8

$$
P F_{r_{i} \rightarrow r_{j}}=\sum_{k=1}^{k} \frac{\operatorname{Abs}\left(P_{k, i}-P_{k, j}\right)}{\mu_{P_{k, i}, P_{k, j}}} \cdot \frac{1}{P F_{M A X}}
$$

where:

- $\quad P_{k, i}$ is the position of the $k^{\text {th }}$ input factor in the ranking obtained by $r_{i}$

- $\quad P_{k, j}$ is the position of the $k^{\text {th }}$ input factor in the ranking obtained by $r_{j}$ 
- $\quad \mu_{P_{k, i}, P_{k, j}}$ is the average of the positions of the $k^{\text {th }}$ input factor in the ranking obtained by $r_{i}$ and $r_{j}$.

- $\quad P F_{M A X}$ is the maximum value of $P F_{r i \rightarrow r j}$ for the number of input factors evaluated

$P F_{r i \rightarrow r j}$ is maximum when the maximum spread of all factors is obtained for the two rankings compared. For instance, for 3 input factors and $P_{1, i}=1, P_{2, i}=2, P_{3, i}=3$ the maximum value of $P F_{r i \rightarrow r j}$ occurs when $P_{1, i}=3, P_{2, i}=1, P_{3, i}=2$ (Cosenza et al., 2013). For 14 input factors $P F_{M A X}$ results in 14.13.On the basis of this position index $P F_{r i \rightarrow r j}$ (Eq. 8) a general criteria for quantifying the convergence of the Morris screening method is established. Based on previous studies, reaching two consecutive $P F_{r i \rightarrow r j}$ values below 0.3 is proposed as criteria for selecting $r_{j}$ as $r_{o p t}$.

Once $r_{\text {opt }}$ was found, the graphical Morris approach was used to identify the factors that influence the model. The $\mu$ and $\sigma$ obtained for all $S E E_{i}$ values of each $F_{i}$ are plotted. Two lines were also plotted, corresponding to $\mu_{i} \pm 2 S E M_{i}$, where $S E M_{i}$ is the standard error of the mean that can be calculated thus: $S E M_{i}=\sigma_{i} / \sqrt{r}$. Factors laying outside the wedge formed by the two lines corresponding to $\mu i= \pm 2 S E M i$ (presenting high $\mu$ and relatively small $\sigma$ ) are deemed in this study to be influential presenting linear and additive effects upon the output. Factors laying inside this wedge that present small $\mu$ but high $\sigma$ are deemed to be influential presenting non-linear or interactive effects upon the output (the factor carries the effect of different signs, depending on the values assumed by the other factors). Factors laying inside/outside this wedge that present small $\mu$ and $\sigma$ are deemed to be less/non-influential factors with negligible effects upon the output (Morris, 1991). 


\subsection{Dynamic calibration of the model being evaluated}

The dynamic calibration (based on optimisation algorithms) of the influential input factors of the model consisted of adjusting the simulated TMP (TMP SIM) to the experimental TMP $\left(T M P_{E X P}\right)$ by means of the least squares method together with the subspace trust region method (Coleman and Li, 1996), based on the interior-reflective Newton method (implemented in MATLAB ${ }^{\circledR}$ LSQNONLIN), and the Runge-Kutta method (MATLAB ${ }^{\circledR}$ ode45 function). The objective function $(O F)$ applied is shown in Eq. 9.

$$
O F=\sum \sqrt{\left(T M P_{S I M}-T M P_{E X P}\right)^{2}}
$$

To enhance the dynamic calibration, appropriate initial values for the model factors had to be selected. In this respect, on the basis of the different Morris simulations carried out to select $r_{\text {opt }}$, the optimum initial values chosen were those which combined to give the minimum least squares error between $T M P_{S I M}$ and $T M P_{E X P}$ (see Eq. 9).

Model performance statistical analysis based on the use of the regression line method was performed by using IBM ${ }^{\circledR}$ SPSS $^{\circledR}$ Statistics v.19 and statgraphics ${ }^{\circledR}$ Centurion v.16.2 were used for model performance statistical analysis.

\section{Results and discussion}

\subsection{Sensitivity analysis results}


The revised version of the Morris screening method was applied to different number of trajectories $(r)$, chosen from $M=1000$ initial Morris trajectories, until the ranking of significant factors remained more or less stable, as measured quantitatively by the index $P F_{r i \rightarrow r j}$. Factor uncertainty was set to $20 \%$ of the variability of the default values shown in Table 2. This value was established on the basis of the results from different trials in which uncertainty ranged from 10 to $50 \%$.

Table 3 shows the resulting $\mu^{*}$ from the model inputs calculated for the different number of runs selected for the Morris simulations. As Table 3 illustrates, higher numbers of runs (i.e. an increase in $r$ ) did not significantly modify the sensitivity measures of the inputs. For instance, increasing the number of runs from 10 to 40 had no significant impact on the rankings of the different model factors.

Table 4 shows $P F_{r i} \rightarrow r j$ for the different number of trajectories evaluated. As can be seen in Table $4, P F_{r i \rightarrow r j}$ was low even when the number of runs was low (e.g. $r=$ 10 40). This means that in this study, values of $r$ below 40 (e.g. $r=10 \sim 30$ ) give a suitable estimate of sensitivity measurements. These results tally with other applications of the Morris screening method involving few repetitions (e.g. $r=10 \sim 20)$ (Campolongo et al., 2011; Ruano et al., 2011).

As previously commented, achieving two consecutives $P F_{r i \rightarrow r j}$ values below 0.3 (i.e. $P F_{r i \rightarrow r j}$ values below $30 \%$ of $P F_{M A X}$ ) was established as the criteria for establishing $r_{j}$ as $r_{\text {opt }}$. In this respect, $P F_{r i \rightarrow r j}$ resulted in a value of 0.3 when $r$ was increased (from 10 to 20) and remained below this threshold value at higher $r$ (from 20 to 40). On the basis of these results, $r=20$ was selected as the optimal number of repetitions $\left(r_{\text {opt }}\right)$ in this study. $r=20$ was considered to be optimal not only because $P F_{10 \rightarrow 20}$ was low but also 
because of the significant stability of the factors at the top of the ranking (see Table 3). In addition, similar results regarding the significant stability of the factors at the ranking were obtained for the case of $r=10 \sim 40$, since $P F_{r i} \rightarrow r j$ remained close to zero. When $r_{o p t}$ $=20,300$ simulations ( simulations $=r \cdot(k+1) ; r=20 ; k=14)$ were required to evaluate the entire model. One simulation (covering 1 month's operations) took approximately 10 minutes to calculate using a PC with $8 \mathrm{GHz}$ Intel ${ }^{\circledR} \mathrm{CORE}^{\mathrm{TM}} \mathrm{i} 5$ processor. Therefore, in this study, it was possible to estimate the sensitivity measures adequately with a low number of repetitions (requiring few calculations). These results suggest adequate coverage of the input space and, therefore, that possible problems related to type I error (i.e. considering a factor to be significant when it is not) and type II error (i.e. failing to identify a factor that influences the model considerably) are minimised.

Figure 1 shows the graphical Morris approach for the optimal number of repetitions selected for the sensitivity evaluation. This figure shows the most influential input factors in the model. Figure 1a shows the 6 most influential input factors, which lie outside the wedge formed by two lines plotted according to $\mu_{i}= \pm 2 S E M_{i}$. They have means substantially different from 0 and relatively small standard deviations. It consisted of: (1) the model factor related to reversible fouling $\gamma_{0}(\mu=-0.527$ and $\sigma=$ $0.185)$; (2) the model factor related to reversible fouling $\beta_{2}(\mu=-0.159$ and $\sigma=0.090)$; (3) the model factor related to reversible fouling $\beta_{1}(\mu=-0.112$ and $\sigma=0.068)$; (4) the factor related to sub-critical fouling $k_{S F}(\mu=-0.089$ and $\sigma=0.051)$; (5) the fouling rate when $\mathrm{J}_{20}$ tends to zero $K_{F}(\mu=-0.060$ and $\sigma=0.038)$; and (6) the maximum membrane scouring velocity $q_{\mathrm{MS}, \mathrm{Max}}(\mu=0.051$ and $\sigma=0.034)$. It is important to note that 3 of the 4 model factors in the sigmoid inhibition function (see Eq. 5) included in process 2 (cake layer removal using biogas sparging to scour the membrane) had the highest mean 
and standard deviation values: $\gamma_{0}, \beta_{2}$ and $\beta_{1}$. These results highlight the importance of these factors for an adequate representation of the filtration results achieved using the developed model. It is important to note that the calibration method proposed for these factors (in addition to $K_{F}$ ) entailed off-line experiments based on the data obtained from different flux-step trials according to Robles et al. (2012). The next in importance were $k_{S F}, q_{\mathrm{MS}, \mathrm{Max}}$ and $K_{F}$. These 3 factors are also related to the reversible fouling mechanisms modelled.

In particular, it is important to highlight the great influence of the factor $\gamma_{0}$, which has the highest $\mu$ (in absolute term) and $\sigma$. According to the Morris theory, factors with high $\sigma$ are expected to have a non-linear or interactive impact on output. Indeed, based on the defined model, $\gamma_{0}$ modifies the impact of other inputs on the model output (interactions between input factors). Finally, $\gamma_{0}$ determines the critical filtration conditions for given MLTS and BRF, and thus affects the final value of $\omega_{C}$ at given operating conditions. Therefore, $\gamma_{0}$ indirectly determines the final value of $\omega_{I}$, which is a direct function of $\omega_{C}$ and $q_{\mathrm{IF}, \mathrm{Max}}$. Both $\omega_{C}$ and $\omega_{I}$ finally determine the model output (TMP). Behaviour similar to $\gamma_{0}$ but to a lesser extent was observed for $\beta_{2}$ and $\beta_{1}$ (both affect critical filtration conditions). On the other hand, the impacts of $k_{S F}, q_{\mathrm{MS}, \mathrm{Max}}$ and $K_{F}$ upon output are expected to be more linear and additive: their mean is quite high and their standard deviation not very high. This behaviour is desirable when estimating factors on the basis of optimisation algorithms.

Six model factors were identified as less/non-influential input factors (see Figure 1b): (1) specific resistance of cake at zero pressure $\alpha_{C, 0}(\mu=-0.018$ and $\sigma=0.004) ;(2)$ proportional constant $k_{R I}(\mu=-0.009$ and $\sigma=0.009)$; (3) maximum irreversible fouling 
kinetic constant $q_{\mathrm{IF}, \mathrm{Max}}(\mu=-0.006$ and $\sigma=0.009)$; (4) half-saturation coefficient for cake solids during membrane scouring and back-flushing $K_{S, X_{m_{C}}}(\mu=-0.005$ and $\sigma=$ $0.003)$; (5) average specific irreversible fouling resistance $\alpha_{I}(\mu=-0.004$ and $\sigma=$ 0.006); and (6) pressure needed to double specific resistance $T M P_{a}(\mu=0.010$ and $\sigma=$ 0.004). It is important to highlight that 3 of the 7 factors identified as less/noninfluential are related to irreversible fouling: $q_{\mathrm{IF}, \mathrm{Max}}, \alpha_{I}$ and $k_{R I}$. The low impact of these factors on the model output was attributed to the expected non-linear or interactive impact on the output of the influential input factors related to reversible fouling.

One aspect to highlight is that only two model factors, the time constant $k_{t}$ and the maximum back-flushing removal velocity $q_{\mathrm{BF}, \mathrm{Max}}$, were identified as non-influential with a value of zero for both sensitivity measures ( $\mu$ and $\sigma$ ). The value of $k_{t}$ is related to the time required for compressing the cake to its equilibrium value for a given TMP level (i.e. increasing $\alpha_{C}$ to $\alpha_{C, T M P}$ ). In this respect, it was assumed that $\alpha_{C, T M P}$ was always achieved independently of the value established for $k_{t}$ within the selected input uncertainty. The effect of this input factor $\left(k_{t}\right)$ on the output is therefore expected to be negligible, therefore this result suggests it is not necessary to calibrate this input factor in this particular application of the model. On the other hand, $q_{\mathrm{BF}, \mathrm{Max}}$ gives the maximum back-flushing removal velocity. Since this factor was identified as noninfluential, it can be assumed that for the back-flushing duration interval evaluated in this study (from 30 to 50 seconds), the reversible cake-layer was completely removed from the membrane surface. Moreover, it is interesting to note that low back-flushing frequencies (1 back-flushing for each 10 filtration-relaxation cycles on average) were applied, therefore this input factor was expected to influence the output less than other inputs (e.g. the input factors related to the removal of fouling by using biogas sparging 
to scour the membrane).

Input factors identified as less/non-influential can be set to default values based on optimisation algorithms. It must be emphasised that these factors are for the input factors whose values were not calibrated off-line beforehand. To be precise, these factors were either dynamically calibrated $\left(\alpha_{C, 0}\right.$ and $\left.T M P_{a}\right)$, or calculated on the basis of experimental data $\left(q_{\mathrm{IF}, \mathrm{Max}}, K_{S, X_{m_{C}}}\right.$ and $\left.k_{R I}\right)$, or set to default values $\left(\alpha_{I}, q_{\mathrm{BF}, \mathrm{Max}}\right.$ and $\left.k_{t}\right)$.

\subsection{Assessment of the modelling approach}

As mentioned before, one main characteristic of the model evaluated in this study is that it was developed on the basis of the operating results of an AnMBR system fitted with industrial-scale membranes. Hence, most of the factors included in the model were defined in order to represent all possible filtration process performances. Indeed, the results of the sensitivity analysis tally with the knowledge of the process because most of the proposed model factors defined and calibrated by off-line experiments were identified as the most influential input factors. In this respect, the factors related to membrane scouring $\left(\beta_{1}, \beta_{2}, \gamma_{0}, K_{F}\right.$ and $\left.q_{\mathrm{MS}, \mathrm{Max}}\right)$ were defined in the model on the basis of trials designed to identify the critical filtration conditions of the AnMBR plant.

As regards the less/non-influential input factors, those related to cake layer build-up and compression during filtration $\left(k_{S F}, \alpha_{C, 0}\right.$ and $\left.T M P_{a}\right)$ and cake layer removal during back-flushing ( $K_{S, X_{m_{C}}}$ ) were included in the model on the basis of experimental results found in recent literature (Bugge et al., 2012; Jørgensen et al., 2012; Sarioglu et al., 2012). As regards irreversible fouling mechanisms, factors $q_{\mathrm{IF}, \mathrm{Max}}, \alpha_{I}$ and $k_{R I}$ were 
included in the model on the basis of experimental results concerning long-term membrane performance (i.e. on the basis of the results showing an increase in the total filtering resistance of the system and a decrease in the critical flux determined in experiments throughout the operating period of the plant).

As regards the input factors identified in this study as non-influential $\left(k_{t}\right.$ and $\left.q_{\mathrm{BF}, \mathrm{Max}}\right)$, the result obtained for $k_{t}$ predicts that this factor can be fixed to a constant value in the model. The result for $q_{\mathrm{BF}, \mathrm{Max}}$ suggests that this input factor is not required in the model definition although this factor was identified as non-influential in this specific study in which low back-flushing frequencies were applied. Therefore, it must be said that this input factor is expected to model the output in other specific situations or model applications (e.g. operating with variable duration, high back-flushing frequencies, modelling short-term process performance, etc.).

\subsection{Model calibration}

For the experimental period evaluated in this study, the 6 influential input factors $\left(\beta_{1}, \beta_{2}, \gamma_{0}, K_{F}, q_{\mathrm{MS}, \mathrm{Max}}, k_{S F}\right)$ were calibrated by an optimisation algorithm, and the other factors were set to the optimised initial values. Table 5 shows the initial values used in this dynamic calibration (column 1) and the calibrated values for the influential input factors mentioned above (column 2). It is important to highlight the results obtained from the dynamic calibration of the highly-influential factors that were previously calibrated by off-line experiments (i.e. $\beta_{1}, \beta_{2}, \gamma_{0}, K_{F}$ and $q_{\mathrm{MS}, \mathrm{Max}}$ ). Specifically, similar values were obtained for these influential factors when calibrated either dynamically or experimentally (see Table 2 and Table 5). Hence, suitable estimation of these factors can be obtained when using parameter estimation methods. 
Figure 2 shows the results of the dynamic model calibration. Figure $2 \mathrm{a}$ shows the average daily values of $J_{20 n e t}, B R F$, and MLTS. Figure $2 b$ shows the average daily $T M P_{S I M}$ and $T M P_{E X P}$. Hence, Figure 2 shows that, even when operating at different MLTS, $J_{20 n e t}$ and BRF levels (see Figure 2a), the model accurately predicted the membrane performance using the calibrated values for the model factors (see Figure 2b): an adequate Pearson Product-Moment correlation coefficient $(R)$ between $T M P_{E X P}$ and $T M P_{S I M}$ was obtained (0.947). Nevertheless, the model also gave accurate results when using the default values (Pearson's $R$ coefficient was 0.898). Hence, the performance of the model was only slightly enhanced by dynamically calibrating the influential model factors because the initial factor values had been calibrated previously using long-term data (Robles et al., 2013a).

In order to validate the results obtained using the dynamically calibrated filtration model, the regression line method was used in this study.

Figure 3a shows the scatter plot of the pairs of modelled and observed TMP data values of the dynamically calibrated filtration model for the same point in time, i.e. the modelled output values are plotted against the corresponding measured (observed) data. According to the results shown in Figure 3a, the relationship between modelled and observed data can be visually described as linear model. Specifically, this linear model significantly approximates to an ideal, unbiased model since it yields a slope line similar to a unity-slope line through the origin (slope and intercept approximate to 1 and 0 , respectively). In addition, no systematic divergence from the slope line is observed, which indicates non unmodelled behaviour (i.e. underestimation or overestimation). In this respect, the R-Squared statistic indicates that the model as fitted explains $89.72 \%$ of 
the variability in the modelled TMP.

The resulting P-value in the Analysis of Variance (ANOVA) of the results shown in Figure $3 \mathrm{a}$ resulted in a value lower than $0.05(\mathrm{P}$-value $=0.0000)$. Therefore, there is a statistically significant relationship between the modelled and observed TMP at the 95.0\% confidence level. Moreover, a hypothesis contrast was conducted to evaluate whether the linear regression model slope is significantly different from the unit. This hypothesis contrast resulted in a P-value above 0.05 , validating the null hypothesis for which the slope equals the unit. Therefore, it can be drawn that there are no statistically significant differences between the modelled and observed TMP at the 95.0\% confidence level. In addition, as mentioned before, the corresponding Pearson ProductMoment correlation coefficient $(R)$ between modelled and observed values equals 0.947, indicating a relatively strong relationship between the variables.

Figure $3 \mathrm{~b}$ shows the studentised residuals, which are the quotient resulting from the division of a residual (the difference between observed and modelled data) by an estimate of its standard deviation (Student's t-statistic), resulting from the linear regression model shown in Figure 3a. Specifically, Figure 3b shows the studentised residual error as dependent variable and the simulation time as descriptor variable. This plot does not reveal high unmodelled behaviour since a nearby uniform spread of residuals is observed (i.e. there is systematic difference from cero and not systematic changes over the descriptor variable). Nevertheless, a slightly higher density of positive values can be observed in this figure, indicating that the dynamically calibrated model slightly tends to overestimate correct values. As Figure $3 b$ shows, two observations resulted in studentised residuals greater than 2 in absolute value, but no observations resulted in values higher than 3 in absolute terms. Therefore, outliers were not 
identified.

On the other hand, the Durbin-Watson (DW) statistic was calculated, which tests the residuals in order to determine if there is any significant correlation. According to Figure 3b, DW indicated a possible serial correlation at the $95.0 \%$ confidence level since the P-value is less than $0.05(\mathrm{DW}=1.190)$. The plot of standardised residuals vs. standardised modelled values resulted in a uniform scatter of the pairs of values, which indicated that the variance is statistically uniform (i.e. homocedasticity of the predictive model). Finally, Kolmogorov-Smirnov-Lilliefors test was performed to assess normality in the residuals. This test resulted in a P-value $>0.05$, thus the stochastic character of the error was statistically confirmed.

Therefore, the statistical analysis confirmed the validity of the results obtained from the dynamically calibrated filtration model.

\section{Conclusions}

A sensitivity analysis of a filtration model for AnMBRs using a revised version of the Morris screening method was conducted. The optimal number of repetitions found in this study $\left(r_{o p t}=20\right)$ was similar to the number of repetitions mainly used in other applications of the Morris screening method. Using the Morris screening method enabled to validate the model: 6 of the model's 14 factors were identified as influential, i.e. the factors calibrated using off-line methods. This tallied with the knowledge of the process because the model was developed on the basis of experimental results.

\section{Acknowledgements}


This research work has been supported by the Spanish Ministry of Economy and Competitiveness (MINECO, Projects CTM2011-28595-C02-01/02) jointly with the European Regional Development Fund (ERDF) which are gratefully acknowledged.

\section{References}

[1] American Public Health Association/American Water Works Association/Water Environmental Federation, 2005. Standard methods for the Examination of Water and Wastewater, $21^{\text {st }}$ edition, Washington DC, USA.

[2] Bugge, T.V., Jørgensen, M.K., Christensen, M.L., Keiding, K., 2012. Modeling cake buildup under TMP-step filtration in a membrane bioreactor: Cake compressibility is significant. Water Res. 46, 4330 $-4338$.

[3] Campolongo, F., Cariboni, J., Saltelli, A., 2007. An effective screening design for sensitivity analysis of large models. Environ. Mod. Soft. 22, 1509 - 1518.

[4] Campolongo, F., Saltelli, A., Cariboni, J., 2011. From screening to quantitative sensitivity analysis. A unified approach. Comput. Phys. Commun. 182, 978 - 988.

[5] Coleman, T.F., Li, Y., 1996. An interior, trust region approach for nonlinear minimization subject to bounds. SIAM J. Optim. 6, $418-445$.

[6] Copp, J.B., 1999. Development of standardised influent files for the evaluation of activated sludge control strategies, IAWQ Scientific and Technical Report Task Group: Respirometry in Control of the Activated Sludge Process - internal report.

[7] A. Cosenza, G. Mannina, P.A. Vanrolleghem, M.B. Neumann, Global sensitivity analysis in wastewater applications: a comprehensive comparison of different methods. Environ. Mod. Soft. 49 (2013), $40-52$.

[8] Cropp, R., Braddock, R., 2002. The New Morris method: an efficient second-order screening method. Reliab. Eng. Syst. Safe., 78, $77-83$.

[9] Derbal, K., Bencheikh-lehocine, M., Cecchi, F., Meniai, A.-H., Pavan, P., 2009. Application of the IWA ADM1 model to simulate anaerobic co-digestion of organic waste with waste activated sludge in 
mesophilic condition. Bioresour. Technol. 100, 1539 - 1543.

[10] Drews, A., 2010. Membrane fouling in membrane bioreactors - Characterisation, contradictions, cause and cures. J. Membr. Sci. 363, $1-28$.

[11] Ferrer, J., Morenilla, J.J., Bouzas, A., García-Usach, F., 2004. Calibration and simulation of two large wastewater treatment plants operated for nutrient removal. Water Sci. Technol. 50, 87 - 94.

[12] Jørgensen, M.K., Bugge, T.V., Christensen, M.L., Keiding, K., 2012. Modeling approach to determine cake buildup and compression in a high-shear membrane bioreactor. J. Membrane Sci. 409/410, $335-345$.

[13] Mannina, G., Di Bella, G., Viviani, G., 2011. An integrated model for biological and physical process simulation in membrane bioreactors (MBRs). J. Membrane Sci. 376, 56 - 69.

[14] Morris, M., 1991. Factorial sampling plans for preliminary computational experiments.

Technometrics. 33, $239-245$.

[15] Naessens, W., Maere, T., Nopens, I., 2012. Critical review of membrane bioreactor models - Part 1: Biokinetic and filtration models Bioresour. Technol. 122, 95 - 106.

[16] Ng, A.N.L., Kim, A.S., 2007. A mini-review of modeling studies on membrane bioreactor (MBR) treatment for municipal wastewaters. Desalination 212, $261-281$.

[17] Robles, A., Ruano, M.V., García-Usach, F., Ferrer, J., 2012. Sub-critical filtration conditions of commercial hollow-fibre membranes in a submerged anaerobic MBR (HF-SAnMBR) system: The effect of gas sparging intensity. Bioresour. Technol. 114, 247-254.

[18] Robles, A., Ruano, M.V., Ribes, J., Seco, A., Ferrer, J., 2013a. A filtration model applied to submerged anaerobic MBRs (SAnMBRs). J. Membrane Sci. 444, 139 - 147.

[19] Robles, A., Ruano, M.V., Ribes, J., Seco, A., Ferrer, J., 2013b. Mathematical modelling of filtration in submerged anaerobic MBRs (SAnMBRs): long-term validation. J. Membrane Sci. 446, 303 309.

[20] Robles, A., Ruano, M.V., Ribes, J., Ferrer, J., 2013c. Factors that affect the permeability of commercial hollow-fibre membranes in a submerged anaerobic MBR (HF-SAnMBR) system. Water Res. 47, $1277-1288$.

[21] Robles, A., Ruano, M.V., Ribes, J., Ferrer, J., 2013d. Advanced control system for optimal filtration in submerged anaerobic MBRs (SAnMBRs). J. Membrane Sci. 430, 330 - 341.

[22] Ruano, M.V., Ribes, J., Ferrer, J., Sin, G., 2011. Application of the Morris method for screening the influential parameters of fuzzy controllers applied to WWTPs. Wat. Scien. Tech. 63, 2199 - 2206. 
[23] Ruano, M.V., Ribes, J., Seco, A., Ferrer, J., 2012a. An improved sampling strategy based on trajectory design for the application of Morris method to systems with many input factors. Environ. Mod. Soft. 37, $103-109$.

[24] Ruano, M.V., Serralta, J., Ribes, J., Garcia-Usach, F., Bouzas, A., Barat, R., Seco, A., Ferrer, J., 2012b. Application of the General Model "Biological Nutrient Removal Model No.1" to upgrade two full-scale WWTPs. Environ. Technol. 33, 1005 - 1012.

[25] Saltelli, A., Tarantola, S., Campolongo, F., Ratto, M., 2004. Sensitivity analysis in practice: a guide to assessing scientific models. Chicester: Wiley.

[26] Sarioglu, M., Insel, G., Orhon, D., 2012. Dynamic in-series resistance modeling and analysis of a submerged membrane bioreactor using a novel filtration mode. Desalination 285, 285 - 294 .

[27] Sin, G., Gernaey, KV., 2009. Improving the Morris method for sensitivity analysis by scaling the elementary effects, In: proceedings of the 19th European Symposium on Computer Aided Process Engineering (ESCAPE 19), 925 - 930.

\section{Figure and table captions}

Table 1. Stoichiometry and kinetic expressions of the processes considered in the model.

Table 2. Default values of factors in the evaluated filtration model. Uncertainty was set to $20 \%$ of the variability of these values in the dynamics simulations.

Table 3. Sensitivity analysis results: sensitivity measures of the model factors for the different values of $r$ evaluated $\left(r_{o p t}=20\right)$.

Table 4. Sensitivity analysis results: position factors $\left(P F_{r i \rightarrow r j}\right)$ for the $r$ evaluated.

Table 5. Initial and dynamically calibrated values for the different model factors in the experimental period evaluated in this study.

Figure 1. (a) Sensitivity analysis results: $\mu$ versus $\sigma$ for the final value of $r_{\text {opt }}$ of 20. (b) Zoom of the sensitivity analysis results in the range of $-0.025<\mu<0.025$ and $0<\sigma<0.02$. Lines correspond to $\mu_{i}= \pm$ $2 \operatorname{SEM}_{i}$. 
Figure 2. Model validation using the optimised model factors values. Average daily values of (a) MLTS, $J_{20 n e t}$ and BRF and (b) $T M P_{E X P}$ and $T M P_{S I M} .{ }^{*} R$ represents the Pearson Product-Moment correlation coefficient between $T M P_{E X P}$ and TMP SIM.

Figure 3. (a) Scatter plot of the pairs of modelled and observed TMP data of the dynamically calibrated filtration model for the same point in time. (b) Studentised residuals resulting from the linear model representing the relationship between modelled and observed TMP data 
Table 1. Stoichiometry and kinetic expressions of the processes considered in the model.

\begin{tabular}{lcccl}
\hline Crocess j & $X_{T S}$ & $X_{m_{C}}$ & $X_{m_{I}}$ & Kinetic expression \\
\hline $\begin{array}{l}\text { 1. Cake layer formation } \\
\begin{array}{l}\text { 2. Membrane scouring by } \\
\text { biogas }\end{array}\end{array}$ & -1 & 1 & & $Q_{20 P} \cdot X_{T S}$ \\
$\begin{array}{l}\text { 3. Cake layer detachment } \\
\text { during back-flushing }\end{array}$ & 1 & -1 & & $q_{M S, M a x} \cdot M_{X_{m_{C}}} \cdot I_{M S} \cdot B R F_{V} \cdot X_{m_{C}}$ \\
$\begin{array}{l}\text { 4. Irreversible fouling } \\
\text { consolidation }\end{array}$ & & -1 & & $q_{B F, M a x} \cdot Q_{20 B F} \cdot M_{X_{m_{C}}} \cdot X_{m_{C}}$ \\
\hline
\end{tabular}


Table 2. Default values of factor in the evaluated filtration model. Uncertainty was set to $20 \%$ of the variability of these values in the dynamics simulations.

\begin{tabular}{lll}
\hline Factor & Units & Default value \\
\hline$q_{\mathrm{MS}, \mathrm{Max}}$ & & 6.31 \\
$q_{\mathrm{BF}, \mathrm{Max}}$ & $\mathrm{m}^{-3}$ & 1 \\
$q_{\mathrm{IF}, \mathrm{Max}}$ & $\mathrm{s}^{-1}$ & $3 \cdot 10^{-07}$ \\
$K_{S, X m C}$ & $\mathrm{~kg} \mathrm{SST}^{-1}$ & 0.2 \\
$\alpha_{C, 0}$ & $\mathrm{~m} \mathrm{~kg}{ }^{-1}$ & $1.02 \cdot 10^{13}$ \\
$T M P_{a}$ & $\mathrm{kPa}$ & 18.9 \\
$k_{t}$ & $\mathrm{~s}^{-1}$ & 1 \\
$k_{S F}$ & $\mathrm{~m} \mathrm{~kg}^{-1} \mathrm{~s}^{-1}$ & $4.09 \cdot 10^{10}$ \\
$K_{F}$ & $\mathrm{~Pa} \mathrm{~s}^{-1}$ & $5.6 \cdot 10^{-4}$ \\
$\beta_{I}$ & $\mathrm{~s}^{2} \mathrm{~m}^{-1}$ & $-2.48 \cdot 10^{8}$ \\
$\beta_{2}$ & $\mathrm{~s} \mathrm{~m}^{2} \mathrm{~kg}^{-1}$ & $5.1 \cdot 10^{4}$ \\
$\gamma_{0}$ & $\mathrm{~s} \mathrm{~m}^{-1}$ & $2.81 \cdot 10^{6}$ \\
$k_{R I}$ & $\mathrm{~s}$ & $1.6 \cdot 10^{-07}$ \\
$\alpha_{I}$ & $\mathrm{~m} \mathrm{~kg}^{-1}$ & $1 \cdot 10^{14}$ \\
\hline
\end{tabular}


Table 3. Sensitivity analysis results: sensitivity measures of the model factors for the different values of $r$ evaluated $\left(r_{\text {opt }}=20\right)$.

\begin{tabular}{|c|c|c|c|}
\hline \multicolumn{2}{|l|}{$r=10$} & \multicolumn{2}{|l|}{$r=20$} \\
\hline Factor & $\mu^{*}$ & Factor & $\mu^{*}$ \\
\hline$\gamma_{0}$ & 0.496 & $\gamma_{0}$ & 0.547 \\
\hline $\boldsymbol{\beta}_{2}$ & 0.151 & $\boldsymbol{\beta}_{2}$ & 0.159 \\
\hline$k_{S F}$ & 0.096 & $\beta_{1}$ & 0.119 \\
\hline$\beta_{1}$ & 0.092 & $k_{S F}$ & 0.089 \\
\hline$K_{F}$ & 0.046 & $q_{\text {MS,Max }}$ & 0.060 \\
\hline$q_{\text {MS,Max }}$ & 0.046 & $\boldsymbol{K}_{F}$ & 0.051 \\
\hline$\alpha_{C, 0}$ & 0.016 & $\alpha_{C, 0}$ & 0.018 \\
\hline$k_{R I}$ & 0.010 & $k_{R I}$ & 0.010 \\
\hline$T M P_{a}$ & 0.009 & $T M P_{a}$ & 0.009 \\
\hline$K_{S, X m C}$ & 0.004 & $K_{S, X m C}$ & 0.007 \\
\hline$q_{\mathrm{IF}, \mathrm{Max}}$ & 0.004 & $q_{\mathrm{IF}, \mathrm{Max}}$ & 0.005 \\
\hline$\alpha_{I}$ & 0.003 & $\alpha_{I}$ & 0.004 \\
\hline$k_{t}$ & 0.000 & $k_{t}$ & 0.000 \\
\hline$q_{\mathrm{BF}, \mathrm{Max}}$ & 0.000 & $q_{\text {BF,Max }}$ & 0.000 \\
\hline \multicolumn{2}{|l|}{$r=30$} & \multicolumn{2}{|l|}{$r=40$} \\
\hline Factor & $\boldsymbol{\mu}^{*}$ & Factor & $\mu^{*}$ \\
\hline$\gamma_{0}$ & 0.599 & $\gamma_{0}$ & 0.527 \\
\hline $\boldsymbol{\beta}_{2}$ & 0.182 & $\beta_{2}$ & 0.159 \\
\hline$\beta_{1}$ & 0.128 & $\beta_{1}$ & 0.116 \\
\hline$k_{S F}$ & 0.097 & $k_{S F}$ & 0.090 \\
\hline$K_{F}$ & 0.068 & $q_{\text {MS,Max }}$ & 0.054 \\
\hline$q_{\text {MS,Max }}$ & 0.062 & $\boldsymbol{K}_{\boldsymbol{F}}$ & 0.051 \\
\hline$\alpha_{C, 0}$ & 0.015 & $\alpha_{C, 0}$ & 0.015 \\
\hline$T M P_{a}$ & 0.015 & $k_{R I}$ & 0.010 \\
\hline$k_{R I}$ & 0.008 & $T M P_{a}$ & 0.008 \\
\hline$q_{\mathrm{IF}, \mathrm{Max}}$ & 0.006 & $K_{S, X m C}$ & 0.005 \\
\hline$K_{S, X m C}$ & 0.005 & $q_{\text {IF,Max }}$ & 0.003 \\
\hline$\alpha_{I}$ & 0.005 & $\alpha_{I}$ & 0.003 \\
\hline$k_{t}$ & 0.000 & $\boldsymbol{k}_{t}$ & 0.000 \\
\hline$q_{\text {BF,Max }}$ & 0.000 & $q_{\mathrm{BF}, \mathrm{Max}}$ & 0.000 \\
\hline
\end{tabular}


Table 4. Sensitivity analysis results: position factors $\left(P F_{r i \rightarrow r j}\right)$ for the $r$ evaluated.

\begin{tabular}{cccc}
\hline$r_{i} \rightarrow r_{j}$ & $10 \rightarrow 20$ & $20 \rightarrow 30$ & $30 \rightarrow 40$ \\
\hline$P F_{r i \rightarrow r j}$ & 0.07 & 0.06 & 0.06 \\
\hline
\end{tabular}


Table 5. Initial and dynamically calibrated values for the different model factors in the experimental period evaluated in this study.

\begin{tabular}{llll}
\hline Factor & Unit & Initial value & Calibrated value \\
\hline$q_{\mathrm{MS}, \mathrm{Max}}$ & & 5.89 & 4.71 \\
$q_{\mathrm{BF}, \mathrm{Max}}$ & $\mathrm{m}^{-3}$ & 1.07 & \\
$q_{\mathrm{IF}, \mathrm{Max}}$ & $\mathrm{s}^{-1}$ & $3 \cdot 60^{-07}$ & \\
$K_{S, X m C}$ & $\mathrm{~kg} \mathrm{SST}$ & 0.19 & \\
$\alpha_{C, 0}$ & $\mathrm{~m} \mathrm{~kg}{ }^{-1}$ & $1.08 \cdot 10^{13}$ & \\
$T M_{a}$ & $\mathrm{kPa}^{-1}$ & 20.1 & \\
$k_{t}$ & $\mathrm{~s}^{-1}$ & 1.2 & \\
$k_{S F}$ & $\mathrm{~m} \mathrm{~kg}^{-1} \mathrm{~s}^{-1}$ & $3.81 \cdot 10^{10}$ & $2.30 \cdot 10^{10}$ \\
$K_{F}$ & $\mathrm{~Pa} \mathrm{~s}^{-1}$ & $4.5 \cdot 10^{-4}$ & $5.4 \cdot 10^{-4}$ \\
$\beta_{I}$ & $\mathrm{~s}^{2} \mathrm{~m}^{-1}$ & $-2.31 \cdot 10^{8}$ & $-1.85 \cdot 10^{8}$ \\
$\beta_{2}$ & $\mathrm{~s} \mathrm{~m}^{2} \mathrm{~kg}^{-1}$ & $4.1 \cdot 10^{4}$ & $4.9 \cdot 10^{4}$ \\
$\gamma_{0}$ & $\mathrm{~s} \mathrm{~m}^{-1}$ & $2.62 \cdot 10^{6}$ & $3.14 \cdot 10^{6}$ \\
$k_{R I}$ & $\mathrm{~s}$ & $1.9 \cdot 10^{-07}$ & \\
$\alpha_{I}$ & $\mathrm{~m} \mathrm{~kg}^{-1}$ & $1 \cdot 20^{14}$ & \\
\hline
\end{tabular}




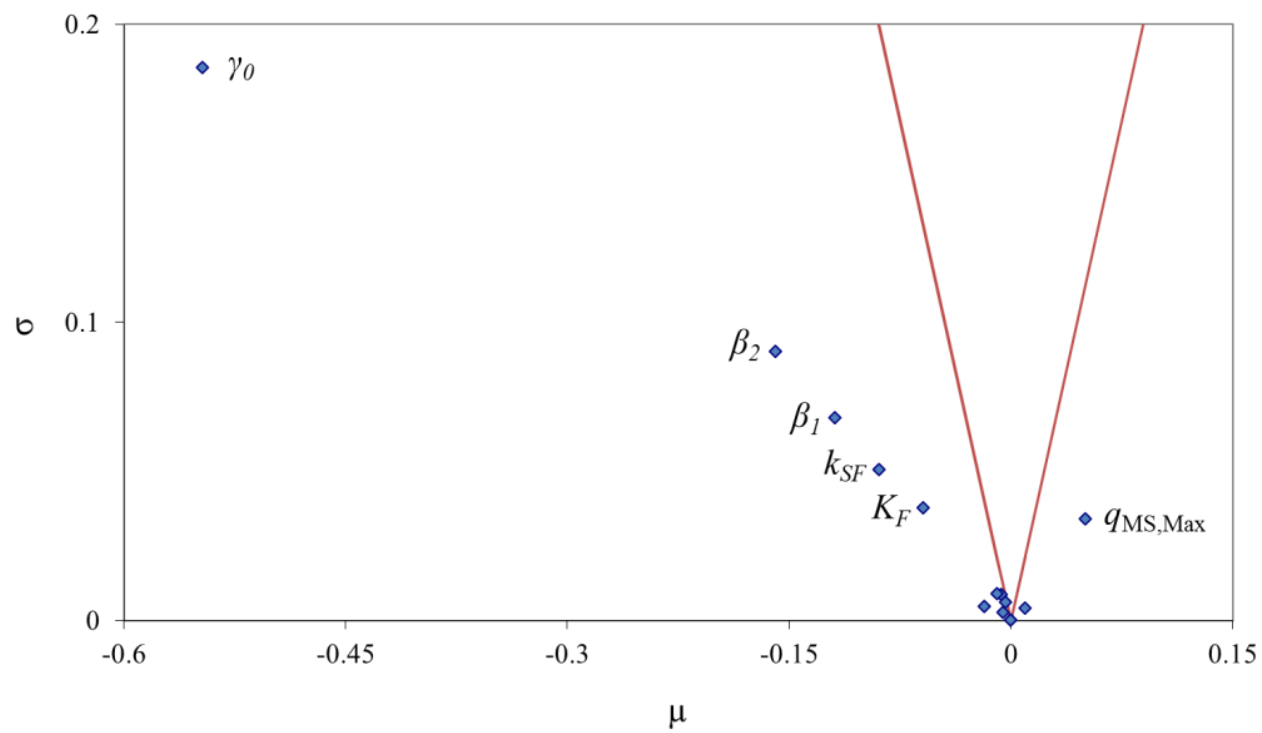

(a)

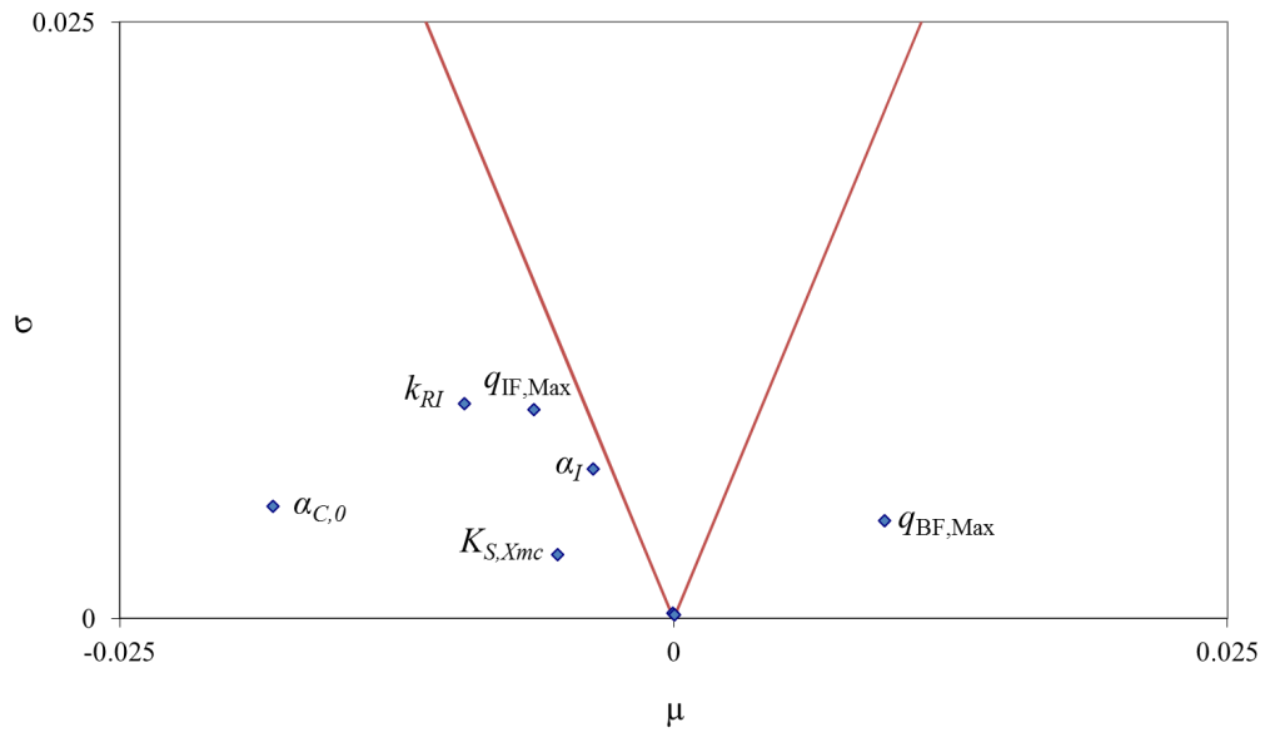

(b)

Figure 1. (a) Sensitivity analysis results: $\mu$ versus $\sigma$ for the final value of $r_{\text {opt }}$ of 20. (b) Zoom of the sensitivity analysis results in the range of $-0.025<\mu<0.025$ and $0<\sigma<0.02$. Lines correspond to $\mu_{i}= \pm$ $2 S_{E M}$. 


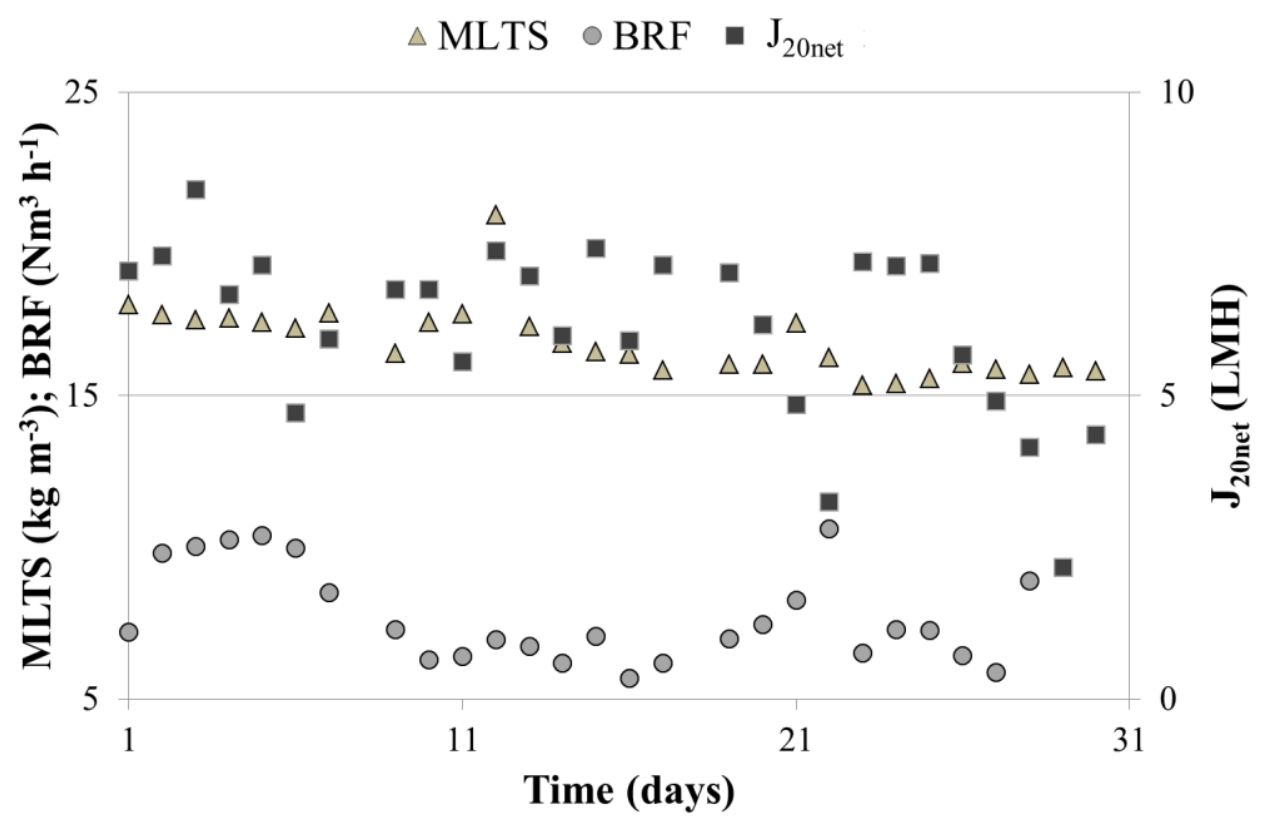

(a)

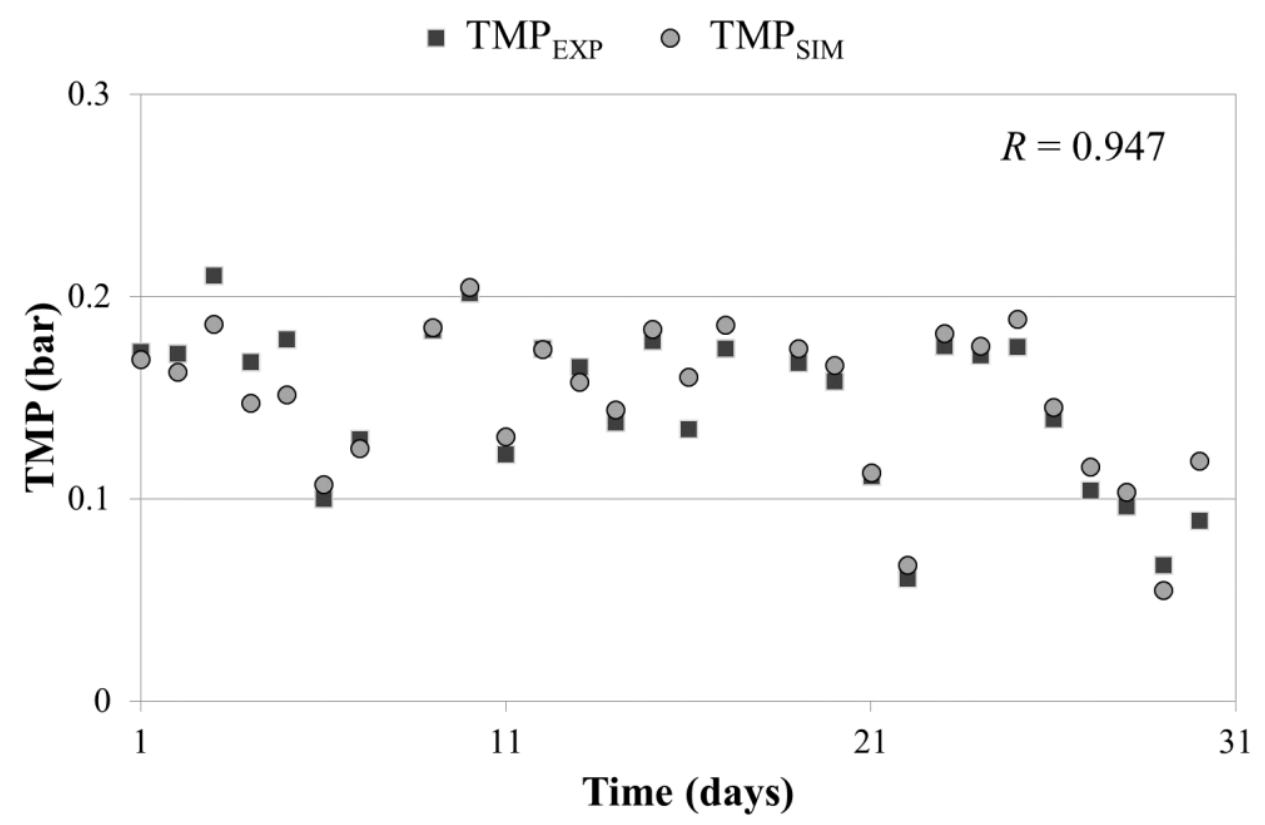

(b)

Figure 2. Model validation using the optimised model factor values. Average daily values of (a) MLTS,

$J_{20 n e t}$ and $\mathrm{BRF}$ and (b) $T M P_{E X P}$ and $T M P_{S I M} .{ }^{*} R$ represents the Pearson Product-Moment correlation coefficient between $T M P_{E X P}$ and $T M P_{S I M}$. 


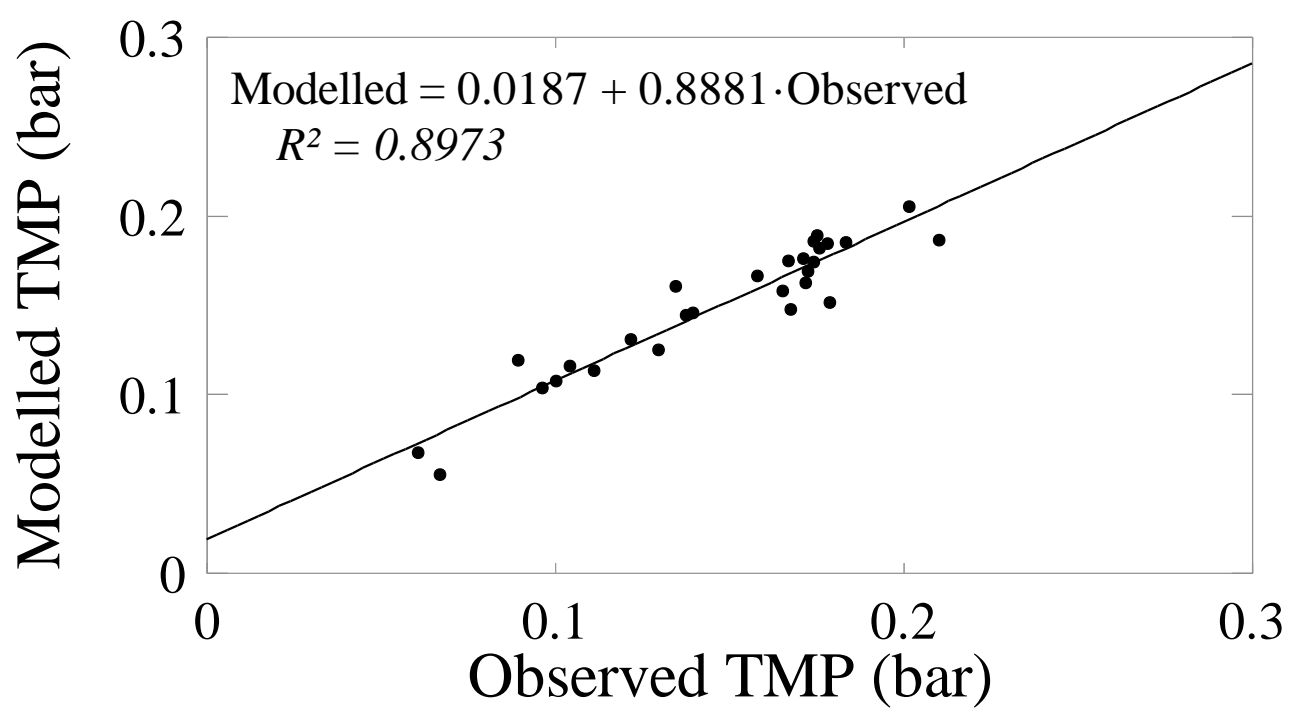

(a)

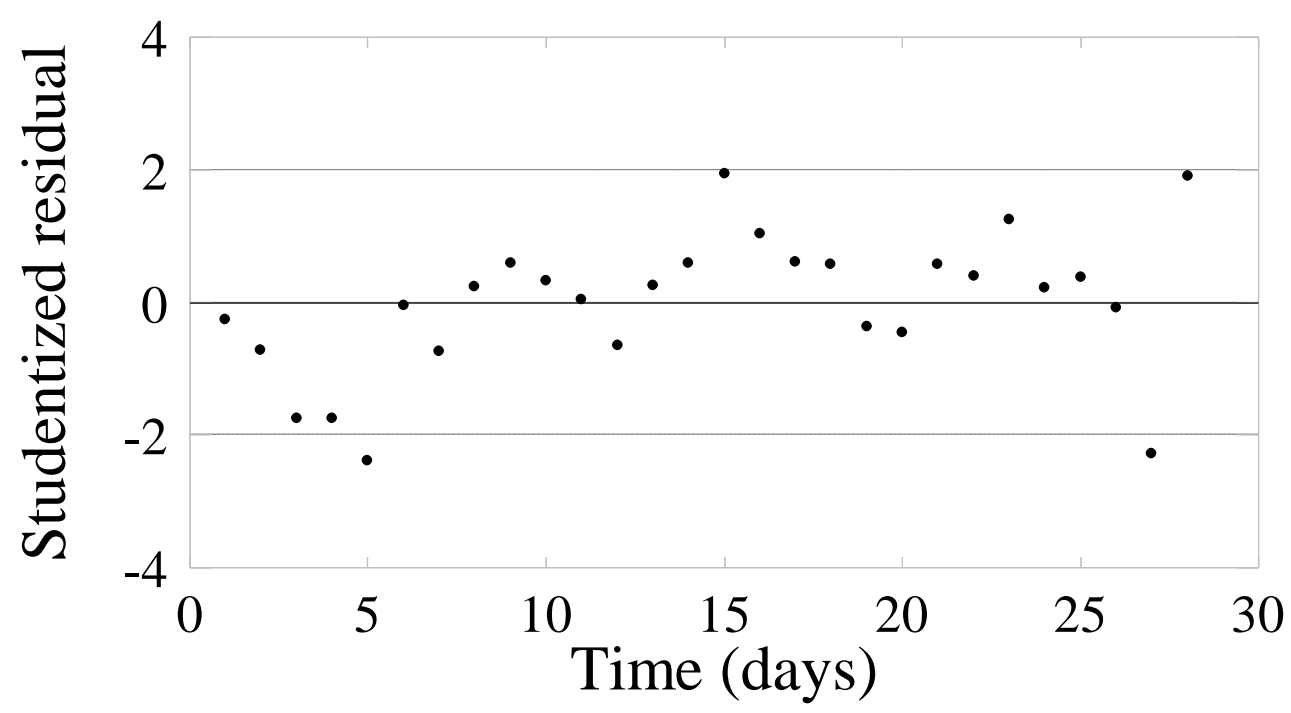

(b)

Figure 3. (a) Scatter plot of the pairs of modelled and observed TMP data of the dynamically calibrated filtration model for the same point in time. (b) Studentised residuals resulting from the linear model representing the relationship between modelled and observed TMP data. 
